\title{
Bilateral lung cancer resection with preservation of an accessory cardiac lobe
}

\author{
Junji Ichinose 조 , Yosuke Matsuura, Masayuki Nakao, Mingyon Mun
}

Department of Thoracic Surgical Oncology, Cancer Institute Hospital of Japanese Foundation for Cancer Research, Tokyo, Japan

\section{Correspondence to \\ Dr Junji Ichinose;}

jichinose-tky@umin.net

Accepted 15 October 2020

\section{DESCRIPTION}

Accessory cardiac bronchus, which usually ends as a blind pouch, has a low incidence rate of $0.07 \%$ $0.5 \%$. Mangiulea et al distinguished three types of accessory cardiac bronchus, namely short type with blind extremity, accessory-lobed type and long diverticular type without bronchial or alveolar arborisation. ${ }^{1-3}$ Here, we present the case of a patient with synchronous bilateral lung cancer and an accessory-lobed type cardiac bronchus. Twostage thoracoscopic right lower lobectomy and left S8 segmentectomy were performed and the accessory lobe was preserved to maintain pulmonary function.

An asymptomatic 66-year-old woman was found to have bilateral lung tumours on medical examination. CT revealed a solid nodule in the right lower lobe and a part-solid nodule in the left lower lobe. Bilateral lung cancer was suspected, and two-stage thoracoscopic right lower lobectomy and left S8

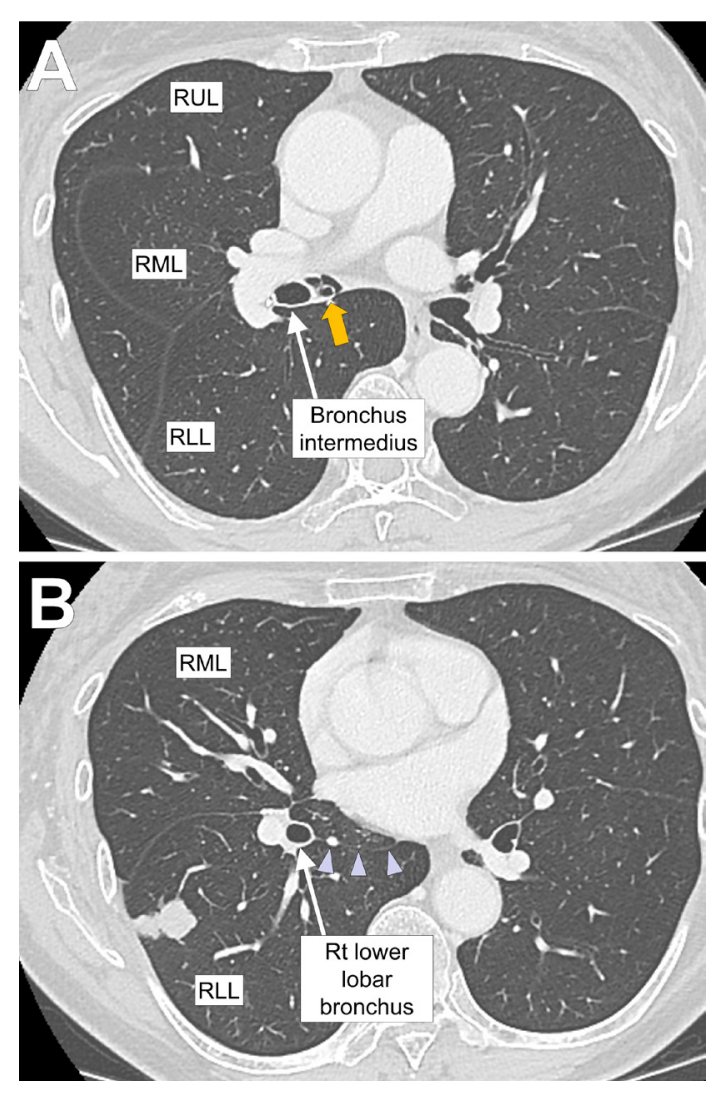

Figure 1 (A) Chest CT showing the accessory lobe-type cardiac bronchus (orange arrow). (B) The interlobar plane between the accessory lobe and the right lower lobe is also shown (purple arrow heads). Rt, right; RLL, right lower lobe; RML, right middle lobe; RUL, right upper lobe.

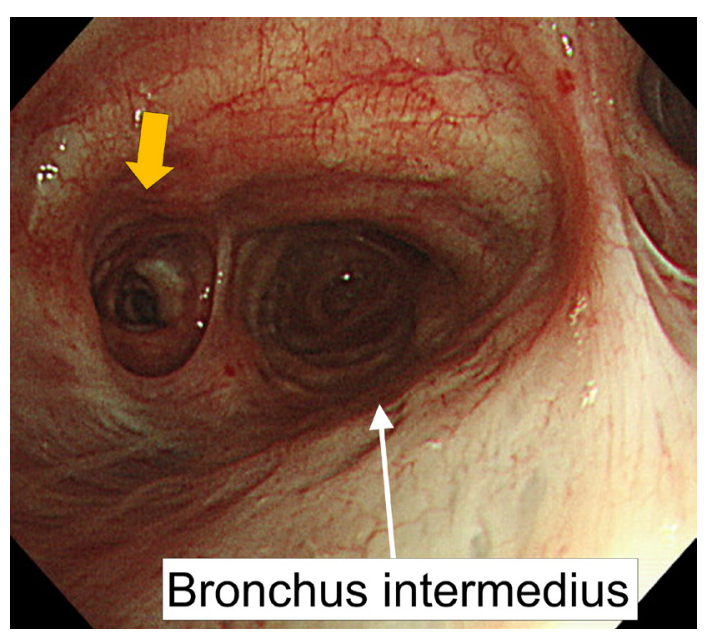

Figure 2 Bronchoscopy showing the accessory cardiac bronchus arising from the medial wall of the bronchus intermedius (orange arrow).

segmentectomy were planned. She was a smoker and had mildly impaired preoperative lung function (the ratio of forced expiratory volume in $1 \mathrm{~s}$ to forced vital capacity was 73\%).

CT and bronchoscopy revealed an accessory cardiac bronchus arising from the medial wall of the bronchus intermedius and a well-ventilated accessory lobe (figures 1 and 2). Three-dimensional

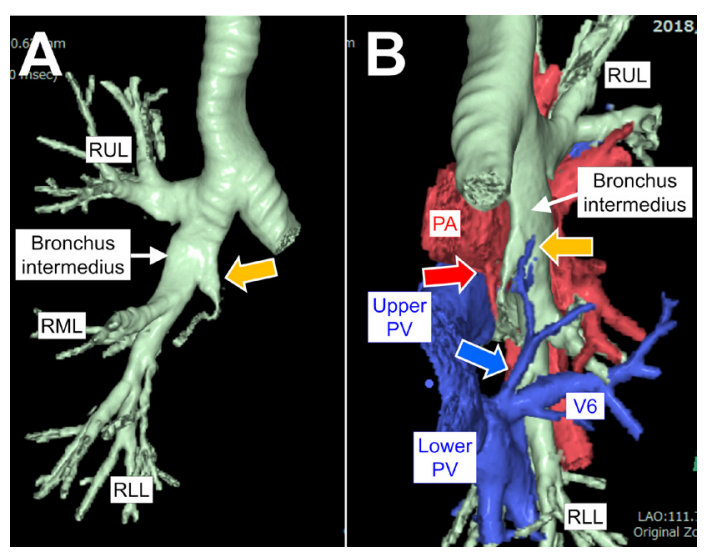

Figure 3 (A) Three-dimensional CT confirming that the accessory cardiac bronchus arose from the bronchus intermedius (orange arrow). (B) The blood vessels of the accessory lobe are a pulmonary artery branching from the right main pulmonary artery (red arrow) and a pulmonary vein branching from the right lower pulmonary vein (blue arrow). PA, pulmonary artery; PV, pulmonary vein; RLL, right lower lobe; RML, right middle lobe; RUL, right upper lobe. 


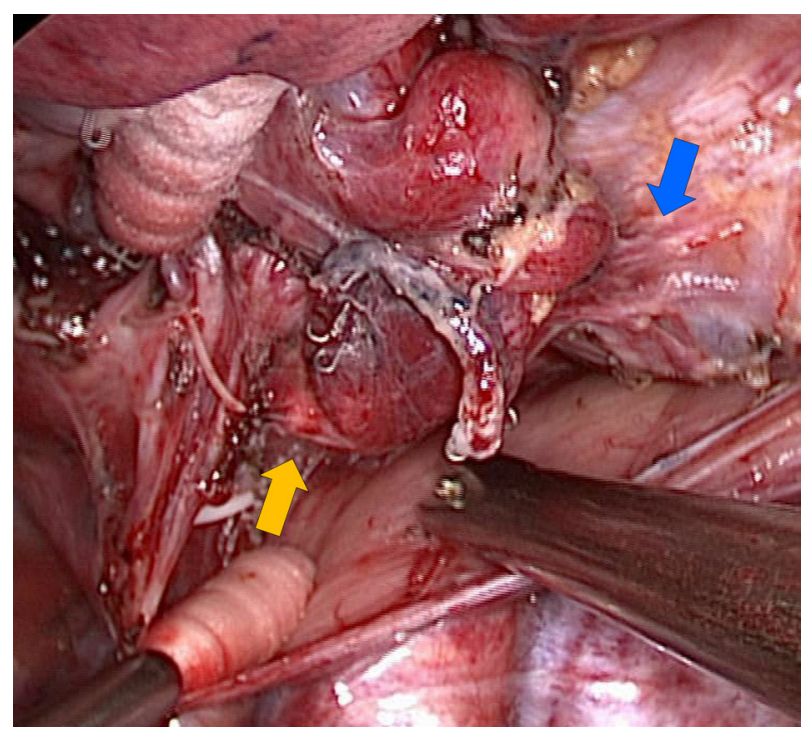

Figure 4 Surgical view after thoracoscopic right lower lobectomy with mediastinal lymphadenectomy. The preserved accessory lobe, its bronchus (orange arrow) and pulmonary vein (blue arrow) are shown.

CT confirmed that the accessory lobe had a pulmonary artery branching from the right main pulmonary artery and a pulmonary vein branching from the right lower pulmonary vein (figure 3). The accessory cardiac bronchus had an inner diameter of $7 \mathrm{~mm}$ and a length of $22 \mathrm{~mm}$. Three-dimensional CT volumetry showed that the accessory lobe volume was $72 \mathrm{~mL}$ and about $8 \%$ of the right lower lobe volume, which corresponds to a subsegment. We did not perform a ventilation and perfusion scan preoperatively.

We considered the contribution of the accessory lobe as clinically significant. Thoracoscopic right lower lobectomy was performed with the preservation of the accessory lobe to maintain pulmonary function (figure 4). The patient's postoperative course was uneventful, and thoracoscopic left S8 segmentectomy was performed after 4 months. Postoperative CT showed sufficient expansion of the accessory lobe, and pulmonary function was well preserved after bilateral lung resection.
In this case, three-dimensional CT clearly showed that the accessory lobe had a pulmonary artery branching from the right main pulmonary artery and a pulmonary vein branching from the right lower pulmonary vein. We confirmed the accessory bronchus and the vein intraoperatively and preserved them.

The accessory lobe presents a potential risk as it is usually small and undeveloped and may therefore be a reservoir of infectious material and a source of haemoptysis. However, in this special case, the accessory lobe was relatively large and well ventilated. The patient had not suffered pneumonia or haemoptysis. Moreover, the patient needed to undergo resection of contralateral lung cancer. She was a smoker and had mildly impaired preoperative lung function. We reckoned that the advantage of sparing the accessory lobe outweighed the potential risk.

\section{Learning points}

- Accessory cardiac bronchus with a well-ventilated accessory lobe is rare. The accessory lobe had a pulmonary artery branching from the right main pulmonary artery and a pulmonary vein branching from the right lower pulmonary vein.

- Bilateral lung cancer resection was performed with the preservation of the accessory lobe to maintain pulmonary function.

Contributors $\mathrm{J}$ contributed to the planning, data collection, analysis and writing of the manuscript. YM, MN and MM contributed to the review of the manuscript.

Funding The authors have not declared a specific grant for this research from any funding agency in the public, commercial or not-for-profit sectors.

Competing interests None declared.

Patient consent for publication Obtained.

Provenance and peer review Not commissioned; externally peer reviewed.

ORCID iD

Junji Ichinose http://orcid.org/0000-0002-3630-5223

\section{REFERENCES}

1 Mangiulea VG, Stinghe RV. The accessory cardiac bronchus. Bronchologic aspect and review of the literature. Dis Chest 1968:54:433-6.

2 White ES. Accessory cardiac bronchus. Am J Respir Crit Care Med 2011;183:825

3 Barreiro TJ, Gemmel D. Accessory cardiac bronchus. Lung 2014;192:821-2.

Copyright 2020 BMJ Publishing Group. All rights reserved. For permission to reuse any of this content visit

https://www.bmj.com/company/products-services/rights-and-licensing/permissions/

BMJ Case Report Fellows may re-use this article for personal use and teaching without any further permission.

Become a Fellow of BMJ Case Reports today and you can:

- Submit as many cases as you like

- Enjoy fast sympathetic peer review and rapid publication of accepted articles

- Access all the published articles

- Re-use any of the published material for personal use and teaching without further permission

Customer Service

If you have any further queries about your subscription, please contact our customer services team on +44 (0) 2071111105 or via email at support@bmj.com.

Visit casereports.bmj.com for more articles like this and to become a Fellow 